\title{
Dicionário de ideias aceitas: projeto de tradução
}

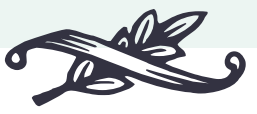

Carolina Messias ${ }^{1}$ e Claudia Amigo Pino

\section{"A" de Apresentação}

Você faz bem em pensar no Dictionnaire des idées reçues. Esse livro completamente pronto e precedido de um bom prefácio, no qual se indicaria como a obra foi feita no sentido de reatar o público à tradição, à ordem, à convenção geral, e organizada de tal maneira que o leitor não saiba se estão zombando dele ou não, seria talvez uma obra estranha e capaz de dar certo, pois seria totalmente feita de atualidades. ${ }^{3}$ (À Louis Bouilhet). 4 de setembro de 1850.

$\overbrace{\text { si }}^{\text {RAD }}$ RADUZIR o Dictionnaire des idées reçues, de Flaubert, para a nossa língua pode ser considerado por si só um lugar-comum. Isso porque o mercado editorial brasileiro já dispõe de algumas traduções desse dicionário que começou a ser pensado pelo escritor em 1850. Dessa gama de opções, destacamos as traduções de Mariana Appenzeller, publicada pela Estação Liberdade em 2007, baseada na edição de Stéphanie Dord-Crouslé, da Flammarion, 1999; e a de Cristina Murachco, publicada pela Nova Alexandria em 1995, que parece ser baseada na edição da Claudine Gothot-Mersh, da Folio Classique, apesar de não ter indicações precisas a respeito.

Neste projeto de tradução, nos baseamos na edição feita por Anne Herschberg-Pierrot a partir do manuscrito autógrafo de Flaubert, uma edição que não é tão divulgada no Brasil. Há três manuscritos do Dicionário, conforme a divisão proposta na edição diplomática de Bowvard e Pécuchet por Lea Caminitit: o manuscrito $a$ (autógrafo) e os manuscritos $b$ e $c$ (que possuem traços do amigo e secretário Edmond Laporte, colaborador do projeto do Dicionário). O manuscrito $b$ é um conjunto de folhas, na maioria, preenchidas a lápis, que se apresenta em forma de rascunho e que pode ser anterior a algumas fichas do manuscrito $c$. Este último é um fichário também com ideias de verbetes para incorporar o Dicionário.

Sobre a cronologia desses três manuscritos, foram levantadas algumas hipóteses: acredita-se que Flaubert tenha começado a trabalhar no manuscrito $a$ e, mais tarde, tenha retomado esse mesmo manuscrito a partir dos manuscritos $b$ e $c$. Segundo Herschberg-Pierrot, "o mais acabado é o manuscrito $a$, redigido por Flaubert e composto a partir dos manuscritos $b$ e $c$, que serviram de reserva de artigos" . Já para Gothot-Mersh, "é muito provável que o manuscrito $a$, que é de sua mão [de Flaubert] e

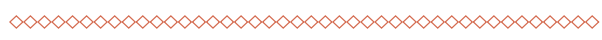

${ }^{1}$ Mestranda do Programa de Estudos Línguísticos, Literários e Tradutológicos em Francês na FFLCH/USP, onde desenvolve pesquisa financiada pela CAPES. Membro do Grupo Criação e Crítica. E-mail: carolina.messias@usp.br

${ }^{2}$ Professora de Literatura Francesa da FFLCH/USP e coordenadora do Grupo Criação e Crítica. E-mail: hadazul@usp.br

${ }^{3}$ “Tu fais bien de songer au Dictionnaire des idées reçues. Ce livre complètement fait et précédé d’une bonne préface où l'on indiquerait comme quoi l'ouvrage a été fait dans le but de rattacher le public à la tradition, à l'ordre, à la convention générale, et arrangée de telle manière que le lecteur ne sache pas si on se fout de lui, oui ou non, ce serait peut-être une oeuvre étrange et capable de réussir, car elle serait toute d'actualité.” À Louis Bouilhet. Damas, 4 septembre 1850. Disponível em: http:// flaubert.univ-rouen.fr/correspondance/conard/outils/1850.htm. Acesso em: 03 out. 2011

${ }^{4}$ FLAUBERT, G. Dictionnaire des Idées Reçues. Édition diplomatique des trois manuscrits de Rouen par Lea Caminiti. Naplea, Liguori-Paris: Nizet, 1966.

5 “Comme on l'a montré récemment, des trois manuscrits du Dictionnaire des Idées reçues, le plus abouti est le manuscrit $a$, rédigé par Flaubert et composé à partir des manuscrits $b$ e $c$, qui ont servi de réserve d'articles." HERSCHBERG-PIERROT. Introduction. In: FLAUBERT, G. Le Dictionnaire des Idées Reçues. Paris: Librairie Générale Française, 1997, p. 36. 
que é o único a não respeitar a ordem alfabética, tenha sido redigido, ou ao menos estava em vias de começar, muito antes dos dois outros." ${ }^{\prime \prime}$ Entre $b$ e $c$, a questão da cronologia é um pouco mais complicada dada a característica móvel das folhas e fichas que compunham esses manuscritos. Apesar disso, acredita-se que Flaubert tenha trabalhado os manuscritos $a$ e $c$ ao mesmo tempo, reformulando-os a partir das inclusões de Laporte.

A edição de Herschberg-Pierrot é diferente da proposta por Gothot-Mersh, que optou por não reproduzir as marcas de rasura, cruzes e barras que aparecem na versão manuscrita. A edição de Gothot-Mersh apresenta, segundo a própria autora, "os textos em sua última versão, após correções (estilo, ordem das frases). A pontuação foi regularizada, a ortografia, modernizada." "Essa experiência de leitura de um dicionário "menos caótico" e "mais bem acabado" persiste nas atuais traduções brasileiras que procuram, além disso, evitar "longas e eruditas explanações sobre a origem dos trocadilhos, os autores das citações, a história dos costumes", pois "seria um contra-senso editorial saturar o livro de referências bibliográficas". Ao contrário, Herschberg-Pierrot apresenta uma "versão do manuscrito revisto sobre o original que propõe ao leitor o texto em produção, com suas hesitações, seus arrependimentos, seus possíveis." ${ }^{\prime 10}$. Os diferentes caminhos adotados pelas edições francesas refletem nas atuais traduções brasileiras e em nosso projeto: encontramos, por vezes, variação de conteúdo entre as traduções de Appenzeller, Murachco e a nossa, seja pela quantidade de verbetes ou pela descrição de cada um deles. Algumas dessas diferenças estão ligadas a opções de tradução, sobretudo do léxico (por exemplo, aqui temos o verbete "aspic" que traduzimos como "áspide", já Murachco optou por "víbora"), outras estão relacionadas especificamente com as edições francesas em que se baseiam e, portanto, no manuscrito adotado por essas edições (por exemplo, na tradução de Appenzeller, encontramos a seguinte descrição do verbete agricultura: "Falta de braços" ${ }^{11}$; em nossa tradução, temos: "Faltam braços [na agricultura]./Đeverŕamos encorajá-la./ Assunto muito chique te conversa. Muito chique mesmo."

Nosso projeto de tradução visa propor uma nova experiência de leitura do Dicionário de Flaubert, a começar pelo título, que deixará de lado a expressão "ideias feitas", atualmente utilizada nas traduções brasileiras. Acreditamos que essa mudança é pertinente, pois é preciso refletir não só sobre

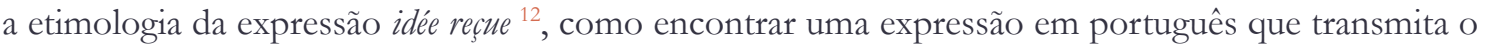
mesmo peso crítico e a mesma ironia que Flaubert utilizou em seu título original. A expressão idée rȩ̣ue é própria do século XVIII e foi adotada com o sentido de ideia ligada a uso comum, ou mesmo a preconceito, por Voltaire. Ainda no século das Luzes, a expressão era relacionada a ideias inquestionáveis, como dogmas religiosos, ou a ideias convenientes no sentido moralista, isto é, ligadas às convenções sociais. Apenas no século XIX, essa expressão adquire o sentido de lugares-comuns, clichês, frases feitas, ideias prontas que eram repetidas sem reflexão pela sociedade, ou seja, sem

$\infty<\infty<\infty<\infty<\infty<\infty<\infty<\infty<\infty<\infty<\infty<\infty<\infty<\infty<\infty<\infty<\infty<\infty<\infty<\infty<\infty<$

6 “[...] il est infiniment probable que le ms a, qui est de sa main, et qui est le seul à ne pas respecter l'ordre alphabétique, a été rédigé, ou tout au moins mis en train, bien avant les deux autres. ” GOTHOT-MERSH, C. Notice. In: FLAUBERT, G. Bouvard et Pécuchet. Paris: Gallimard/Folio Classique. [1979], 2009. p. 434.

GOTHOT-MERSH, Claudine. Idem. p. 436-7

${ }^{8}$ MURACHCO, Cristina. Ao leitor. in: FLAUBERT, G. Dicionário das idéias feitas. São Paulo: Nova Alexandria, 1995. P. 3

${ }^{9}$ NOTA dos editores. In: FLAUBERT, G. Bouvard e Pécuchet. trad: Marina Appenzeller. São Paulo: Estação Liberdade, 2007. p. 9.

10 ' $\mathrm{C}$ 'est ce manuscrit que nous éditons en transcrivant le texte, avec ses ratures. Après l'édition diplomatique des trois manuscrits par Lea Caminiti (1966), et l'édition critique du ms a (sans les articles rayés) par Marie-Thérèse Jacquet (1990), il a paru intéressant de donner une version du manuscrit revue sur l'original, qui propose au lecteur le texte en travail, dans ses hesitations, ses repentirs, ses possibles.” HERSCHBERG-PIERROT. Idem. p. 41 (grifo nosso)

${ }^{11}$ FLAUBERT, G. Dicionário das idéias feitas. In: Bouvard e Pécuchet. trad: Marina Appenzeller. São Paulo: Estação Liberdade, 2007 p. 365

${ }^{12}$ Para mais detalhes, recorrer à introdução de Anne Herschberg-Pierrot ao Dictionnaire des idées reçues (pp. 14-17) e ao artigo da mesma autora, "Histoire d'idées reçues", in: Romantisme, 1994, n86. Langue et idéologie. pp. 101-120. 
autoria ou originalidade, motivo pelo qual os escritores passaram a recusá-las em seus escritos. O título escolhido por Flaubert carrega um peso histórico e irônico, como podemos reconhecer em sua Correspondência, por exemplo, quando trata do prefácio do Dicionário:

Seria a glorificação histórica de tudo o que se aprova. Eu demonstraria que as maiorias sempre tiveram razão, e que as minorias sempre estiveram erradas. Sacrificaria grandes homens a todos os imbecis, os mártires a todos os carrascos, e isso num estilo levado ao exagero, a foguetes. [...] Entraria por aí na ideia democrática moderna de igualdade, nas palavras de Fourier, de que os grandes homens se tornarão inúteis; e é com esse objetivo, diria eu, que esse livro é feito. Encontrar-se-ia, então, em ordem alfabética, sobre todos os assuntos possíveis, tudo o que se deve dizer na sociedade para ser um homem conveniente e amável ${ }^{13}$. (À Louise Colet, 17 de dezembro de 1852)

Esse Dicionário é, portanto, como um manual de ideias "politicamente corretas" da sociedade do século XIX, ou um manual de etiqueta de conversa da burguesia francesa, portanto, um dicionário de ideias irônicas. Nesse sentido, a escolha pela tradução do título como Dicionário de ideias aceitas não é definitiva, pois poderíamos enfatizar outras acepções da expressão idées reçues, como "ideias prontas", "ideias conhecidas", “ideias evidentes", além das já mencionadas anteriormente.

Para compreendermos o contexto em que os verbetes do Dicionário se inserem, optamos por traduzir todas as notas de rodapé da edição de Herschberg-Pierrot, pois elas permitem, além disso, leituras cruzadas com boa parte da obra flaubertiana. Essas leituras cruzadas, por vezes, podem se relacionar com a própria composição desse dicionário, que divide espaço com outros projetos de Flaubert, como a redação de Madame Bovary, entre 1851 e 1856, e da segunda versão de A tentação de Santo Antão entre maio e outubro de 1856, ou mesmo a composição de sua "enciclopédia crítica em farsa" Bouvard e Pécuchet, projeto sobre o qual Flaubert refletiu por muitos anos e cuja redação iniciou em outubro de 1874. O Dicionário acaba se tornando uma parte do projeto Bouvard e Pécuchet e é publicado pela primeira vez junto com a obra inacabada de Flaubert em 1910, numa edição feita por E. L. Ferrère, pela Conard. Ele só será publicado separadamente em 1913, pela mesma casa de edição.

Outro cruzamento pode ser representado pelas contribuições de Edmond Laporte ao longo da redação do Dicionário de Flaubert. Enquanto ele recopiava o manuscrito de Flaubert, também acrescentava outros lugares-comuns, que foram trabalhados em conjunto com Flaubert. Assim, os mesmos verbetes e descrições podem ser encontrados em diferentes versões do manuscrito do Dicionário, ora sob o traço do escritor, ora sob o do amigo/secretário.

Diante de tantos cruzamentos, resta-nos talvez o mais interessante: o de línguas. A tradução do Dicionário do francês para outras línguas, no nosso caso o português brasileiro, movimenta a ordem alfabética, que pode ser confundida com um tipo de organização imposto e estático, já que se trata de uma "convenção milenar"

Ao contrário do que se pode imaginar como lugar-comum para a ordem dos dicionários, traduzir o Dicionário de Flaubert faz movimentar as palavras pelo espaço das páginas, já que alguns verbetes estão em uma letra no original em francês e ocupam outra letra na tradução (como o verbete ÁGUA, que ocupa a lista da letra E, EAU, em francês). Nesse sentido, a lista de palavras de cada letra pode variar de língua para língua, ou seja, nenhuma tradução do Dicionário é igual, o que é extremamente

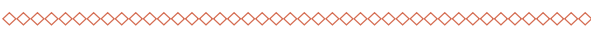

13 “Ce serait la glorification historique de tout ce qu'on approuve. J'y démontrerais que les majorités ont toujours eu raison, les minorités toujours tort. J'immolerais les grands hommes à tous les imbéciles, les martyrs à tous les bourreaux, et cela dans un style poussé à outrance, à fusées. [...] Je rentrerais par là dans l'idée démocratique moderne d'égalité, dans le mot de Fourier que les grands hommes deviendront inutiles; et c'est dans ce but, dirais-je, que ce livre est fait. On y trouverait donc, par ordre alphabétique, sur tous les sujets possibles, tout ce qu'il faut dire en société pour être un homme convenable et aimable." À Louise Colet, 17 décembre 1852.

${ }^{14}$ BARTHES, R. Fragments d'un discours amoureux. In: Oeuvres Complètes. V. 5. 1977-1980. Paris: Seuil, 2002. p. 65. 
interessante para pensar um trabalho sempre em continuação e que possui um inacabamento de princípio, até das próprias línguas, que estão em constante mudança.

Além disso, o Dicionário flaubertiano subverte a proposta da estrutura do dicionário, desestabilizando o significado dos vocábulos principais e construindo um espaço de crítica e de humor, como veremos na tradução dos verbetes da letra A, em português, claro.

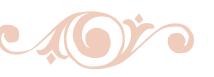

\section{A}

ABELARDO: Inútil ter a menor ideia de sua filosofia, ou mesmo conhecer o título de suas obras.

- Fazer uma alusão discreta à mutilação operada nele por Fulbert.

- Túmulo de Abelardo e Heloisa - se provarem a vocês que é falso exclamar "Vocês desfazem as minhas ilusões". ${ }^{15}$

ABSINTO: Veneno extraviolento. Uma taça e voế morre. Matou mais soldados que os Beduínos ${ }^{16}$.

ACADEMIA FRANCESA: Denegri-la, mas tentar fazer parte dela, se possível ${ }^{17}$.

AÇOUGUEIROS: São horríveis em tempos de Revolução.
${ }^{15}$ As obras filosóficas do teólogo Pedro Abelardo (10791142) são editadas no século XIX por Victor Cousin, que publicou em 1836 as Ouvrages inédits d'Abailard pour servir à l'bistoire de la philosophie scolastique ("Obras inéditas de Abelardo para servir à história da filosofia escolástica"), precedidas por um prefácio, e no final dos anos 1840 começa a publicação das obras completas de Abelardo (em latim). Mas é sobretudo o mito dos amantes infelizes (Abelardo, castrado por Fulbert, o tio de Heloísa), que interessa ao público. Em 1800, Alexandre Lenoir mandou construir uma capela em estilo neogótico no Museu dos Monumentos Franceses para Abelardo e Heloísa, cujos corpos foram transferidos da Abadia de Paraclet. Quando o museu foi destruído, em 1817, o túmulo foi transportado para o Cemitério de Père-Lachaise [Paris].

Abelardo ocupa um lugar na seção "Grandes homens" dos dossiês para o segundo volume de Bouvard e Pécuchet, como alvo dos Libre Penseurs ("Livres-pensadores"), de Louis Veuillot: "Abelardo, esse coitado" (Sottisier, n 1461, bibl. Mun de Rouen, ms g 226, f० 42).

${ }^{16} \mathrm{O}$ absinto, transformado em um álcool mítico no século XIX, era também a bebida das colônias. Em Bouvard e Pécuchet, evoca-se "a fadiga dos acampamentos militares, o absinto e as febres" (BP p. 108 ), a respeito de Gorgu, um vagabundo, que deve ter "lutado sete anos na África" (alusão à conquista da Argélia). O Beduíno representava há muito tempo para Flaubert um modelo de fidelidade solitária e de liberdade frente à ordem social. "Não quero fazer parte de nada, nem ser membro de nenhuma academia, de nenhuma corporação, nem de associação alguma. Eu odeio o bando, a regra e o nível. Beduíno o quanto quiser; cidadão, nunca”. (Carta a L. Coulet, 23 de janeiro de 1854).

${ }^{17}$ Flaubert foi sempre fiel à sua recusa às academias, ao contrário de seu amigo Maxime du Camp, eleito em fevereiro de 1880 à Academia Francesa. Flaubert escreve-lhe nesse momento: "Você se lembra de uma caricatura feita há algum tempo, em Croisset, entre você, eu e Bouilhet? Foi nossa recepção mútua na Academia Francesa!...” (27 de fevereiro de 1880). 
ADVOGADOS: Há Advogados demais na

Câmara.

Têm o juízo deturpado de tanto pleitear prós econtras.

Dizer de um advogado que se expressa mal: "É, mas ele conhece bem as leis".

ÁGUA: A água de Paris dá cólicas ${ }^{18}$ A água do mar nos sustenta para nactar A água de Colônia é cheirosa

AGENTES DA BOLSA: Todos ladrões. AGRICULTURA: Faltam braços [na agricultura]. ${ }^{19}$

Đeveríamos encorajá-la. Assunto muito chique de conversa. Muito ehique mesmo. ${ }^{18}$ É a opinião de Homais: “E depois, a água de Paris, veja
só!" (B, p. 238).

\begin{abstract}
${ }^{19}$ Essa expressão é considerada como um "velho clichê gasto" por Roger Alexandre (Le Musée de la conversation, Paris, Bouillon, 1892) que cita um relatório de um certo Rameville ao Ministro de Agricultura, no Le Moniteur Universel de 20 de julho de 1850: "Senhor Ministro, faltam braços na agricultura em muitos lugares" (Ed. Caminiti 1966). Nas suas notas, Flaubert destaca como "contrária aos lugares-comuns" esta frase do Curso de Agricultura de Gasparin: "Na agricultura na França abundam os braços, contra o senso comum, mas falta capital" ( $m s \mathrm{~g} 226$, fo $26 \mathrm{v}$ Ed. Caminiti 1992). O elogio da agricultura é também um dos pontos fortes do discurso dos Comícios em Madame Bovary.
\end{abstract}

\author{
ALABASTRO ${ }^{20}$ : Serve para deserever as partes \\ mais belas do corpo da mulher.
}

\author{
ALCEBÁADES: Célebre pelo rabo de setr \\ eachorro. $^{21}$
}

ALCOOLISMO: Causa de todas as doenças modernas. $^{22}$

${ }^{20} \mathrm{O}$ alabastro designa a brancura cintilante da pele nos clichês poéticos. Nas obras de juventude de Flaubert, encontramos as expressões: "pescoço de alabastro", "costas de alabastro", "seios de alabastro"..., que fazem parte da fraseologia ideal da descrição.

21 "Alusão a um ato de excentricidade louca de Alcebíades, que cortou o rabo de um cão incrível para continuar chamando a atenção dos frívolos atenienses" (Larousse). A anedota sobre Alcebíades, general e político ateniense (aprox. 450 - 401 a. C.) transformou-se em uma alusão histórica que servia para "caracterizar uma ação singular, original, que não tem outro fim além de fazer falarem dele e de provocar a curiosidade". Flaubert brinca aqui evidentemente com a formulação elíptica e os trocadilhos. Ele evoca a anedota na sua Correspondência: "Uma ação fútil esconde quase sempre um motivo sério. Alcebíades fez cortar o rabo de seu cão para desviar a atenção dos atenienses". (A L. Bouilhet, 2 de junho de 1850).

${ }^{22}$ Manuscrito c (Ficha de Flaubert): “Causa da degeneração da espécie humana e causa de todas as doenças". Homais é um dos porta-vozes do discurso higienista: "Deveríamos tratar com mais rigor a bebedeira! Eu gostaria que nós inscrevêssemos, quinzenalmente, na porta da prefeitura, sobre um quadro ad hoc, os nomes de todos aqueles que, durante a semana, tenham se intoxicado com alcoóis”. (B, p. 278)

ALCORÃO: Livro de Mohamed, que só fala de mulheres. 
ALEMÃES: Povo de sonhadores (velhos). ${ }^{23}$

ALFÂNDEGA: Devemos nos revoltar contra ela - e fraudá-la.

ALGARAVIA: Maneira de falar dos estrangeiros.

Sempre rir do estrangeiro que fala mal francês.

АLHЮ: Mata os vernes intestinais e dá energia para os combates do anor.

Esfregaram-no nos lábios de Henrique IV, quando este veio ao mundo. ${ }^{24}$

\section{[ALMOÇO DE RAPAZES: Exige as ostras, 0} vinho branco e piadas sujas.]

ALOE VERA ${ }^{25}$ : Enfeita teu pinico, com um barulho de eanhão.

AMÉRICA: Um belo exemplo de injustiça: foi Colombo quem a descobriu e ela tira deve seu nome a Américo Vespúcio.

- Fazer uma passagem sobre o governo próprio [self-government.${ }^{26}$

\begin{abstract}
${ }^{23}$ A associação da Alemanha com o país dos sonhos, da imaginação e da especulação filosófica, provém do pensamento romântico. Na Educação sentimental de 1845, o burguês Gosselin examina os livros de seu filho: "Vamos, agora Schiller! Em alemão! Quimeras, sonhos alemães!” (ES, 1845, p.255). Por outro lado, à pergunta de Emma: "E que música você prefere?”, Léon responde: “Oh, a música alemã, aquela que nos leva a sonhar” ( $B$, p. 186). O próprio Flaubert declarava em 1853: "No fundo, eu sou alemão! Foi à força de muito estudo que eu pude sair de todas as minhas brumas setentrionais" (A L. Colet, 25 de junho de 1853). Ora, após a derrota de 1870, surge um discurso totalmente diferente sobre a Alemanha, expresso nas fichas "Alemães" (riscado) e "Alemanha" do manuscrito c: "ALEMÃES. Não é impressionante que eles tenham nos vencido, nós não estávamos prontos". "Alemanha. Sempre precedida de "loura, sonhadora', mas que organização militar!". Flaubert preferiu visivelmente destacar o efeito datado.
\end{abstract}

24 "O alho é o vermífugo mais poderoso e mais inofensivo que eu conheço"(Raspail, citado por Larousse, no verbete "Alho"). A medicina de François-Vincent Raspail, tão popular no século XIX, serve em um momento como referência a Bouvard e Pécuchet, para a terapia à base de cânfora: "A clareza da doutrina os seduz. Todas as doenças provêm dos vermes. [...] A cânfora é o que há de melhor para se livrar deles" (BP. p.128). A anedota sobre Henrique IV - de acordo com a imagem habitual desse Rei: boa-vida, mulherengo - encontra-se no Larousse: "Quando Henrique IV veio ao mundo, seu avô esfregou em seus lábios um dente de alho".

${ }^{25}$ Planta que dá origem a uma resina purgativa. (N. T.)

${ }^{26}$ A história de Cristóvão Colombo e Américo Vespúcio é uma das "pérolas históricas" do século XIX. O governo próprio (Self-government) faz referência ao modelo federalista dos Estados Unidos da América (1835 e 1840). Édouard Laboulaye (1811 - 1833) é o mediador dessas ideias sobre o Segundo Império (Histoire des États-Unis [História dos Estados Unidos], 1855 - 1866): a descentralização é de fato uma questão em voga nos anos 1860 -1870 (ela aparece também na discussão das personalidades de $A$ educação sentimental, e de Bouvard e Pécuchet no fim dos anos 1840). Sobre a história da recepção na França de Tocqueville, ver Françoise Mélonio, Tocqueville et les Français, Ed. Aubier, "Histórias", 1993. 
ANJO: Funciona bem no amor e na Literatura. ${ }^{27}$

ANTIGUIDADE: e tudo relacionado a ela, banal, chato. ${ }^{28}$

ANTIGUIDADES (As): São sempre de fabricação moderna.

APARTAMENTO DE SOLTEIRO: Deve
estar sempre en desordem. Com bugigangas de
mulher espalhadas pelo ehão aqui e ali- - cheiro
de eigarro. A eama e o Devennos eneontrar ali
eoisas extraordinárias.

AR: Sempre tesconfrar das correntes de ar. ${ }^{30}$ Invariavelmente a temperatura do vento está sempre em contradição com a temperatura ambiente. Quando ela está quente, ele está frio quando ela está quente e vice-versa.

ARQUIMEDES: Ao ouvir ser nome, dizer Eureca.

Dêem-me um ponto de apoio, e eu levantarei o mundo.

Há também o parafuso de Arquimedes, mas não é necessário saber no que ele consiste. ${ }^{31}$

ARQUITETOS: Fodos imbecis. Esquecem sempre a escada das casas. ${ }^{32}$
${ }^{27}$ É o cúmulo da designação idealizante, rejeitada frequentemente por Flaubert. A formulação do lugar-comum aparece no meio das notas preparatórias para Bouvard e Pécuchet. "Dicionário de lugares-comuns. Anjo. Funciona bem na literatura" (BP, Ed. Cento, p. 207). A ideia é copiada em uma pequena ficha autobiográfica, hoje colada no manuscrito c. $\mathrm{O}$ texto do manuscrito $a$ parece resultante dessa redação e da menção do manuscrito b: "Amor, poesia".

${ }^{28}$ Por outro lado, é conhecida a forte atração de Flaubert pela antiguidade e tudo aquilo relacionado a ela. "Eu me embriago com a antiguidade, assim como outros o fazem com o vinho" (A E. Feydeau, 12 de novembro de 1859).

${ }^{29}$ Esse imaginário tem um ponto em comum com os desejos do jovem Léon de partida para Paris: "Ele mobiliou, na sua cabeça, um apartamento. Ele levaria lá uma vida de artista!" (B, p. 232). Rodolfo ilustra também o lugar-comum com sua caixa de lembranças, "encontrando ali misturados buquês, ligas, uma máscara negra, alfinetes e mechas de cabelos".(B, p.340)

${ }^{30}$ Homais desconfia das corizas e Bouvard e Pécuchet, que, abalados pelas suas leituras médicas, têm medo de todas as doenças: "Entristecendo-se mutuamente, eles olhavam suas línguas, mediam seus pulsos, mudavam de água mineral, purgavam-se; e temiam o frio, o calor, o vento, a chuva, as moscas e, principalmente, as correntes de ar" (BP p. 134).

Flaubert cita frequentemente o clichê "brisa fresca" (fond de l'air) em sua Correspondência. Ele aparece também no espetáculo do Castelo dos corações. No $5^{\circ}$. Ato, cena 2: "TODOS OS BURGUESES aparecem em suas janelas, estendem a mão e dizem: faz calor! UMA MULHER chega em cada janela: Sim! Mas a brisa está fria. TODOS OS BURGUESES: De fato!" (Teatro, p. 347)

${ }^{31}$ Arquimedes é o exemplo de um sábio reduzido a alguns "floreios históricos"; "Eureca" "“encontrei", exclamação que ele teria pronunciado após ter descoberto durante o banho o princípio da pressão exercida sobre seu corpo submerso em um fluido), a teoria da alavanca e do parafuso sem fim. "Que me dêem um ponto de apoio e eu levantarei o mundo" é uma alusão histórica corrente. $\mathrm{O}$ artigo foi redigido a partir de uma ficha pessoal de Flaubert no manuscrito c.

${ }^{32} \mathrm{O}$ julgamento pode remeter à concorrência entre arquitetos e engenheiros na segunda metade do século XIX: à formação neoclássica da Escola de Belas Artes, fundada essencialmente sobre o desenho e a composição, se opõe a formação das escolas de engenheiros (a Escola Politécnica, que fornece todos os engenheiros do Estado, de diferentes áreas e, após 1829, a Escola Central das artes e manufaturas, que forma os engenheiros civis). A Revue générale de l'architecture (Revista geral de arquitetura), dirigida por César Daly, torna-se eco dos debates sobre a formação do arquiteto e sobre as relações entre engenheiros e arquitetos. Sobre a questão, ver Siegfried Giesion, Espace, temps, architecture (Espaço, tempo, arquitetura), Denoël, 1978, e o catálogo da exposição do museu d'Orsay, La carrière de l'architecte an XIXe siècle (A carreira do arquiteto no século XIX) por Annie Jacques (“Les Dossiers du musée d'Orsay”, no. 3, 1986). 
ARQUITETURA: Há somente quatro tipos de arquitetura. Claro, sem contar o egípcio, o ciclópico, o assírio, o indiano, o chinês, etc. gótico, romano, etc. ${ }^{33}$

ARSÊNICO: Encontra-se em todas partes! Lembrar de Madame Lafarge. ${ }^{34}$

No entanto, há povos que o comem!

ARTES: São bastante inúteis - já que podemos substitúf-las por máquinas meeânieas que fazem fabrieam melhore mais rápido prontamente.

ARTISTAS: Todos farsantes.

Elogiar o desinteresse deles (velhos).

Surpreender-se quando estiverem vestidos

eomo todo mundo. (velhos).

- Ganhram quantidactes absurdas, mas jogam

tucto peta janeta.

Frequentemente são convidados para jantar ent atgum salão.

Artista mulher só pode ser vadia.
${ }^{33}$ Segundo o Dictionnaire de la conversation (Dicionário da conversação), distinguem-se classicamente cinco tipos de arquitetura, segundo a forma particular das colunas e de seus entabulamentos: os três tipos gregos (o dório, o iônico e o coríntio) e os dois tipos romanos (a ordem compósita ou romana e o tipo toscano, de origem etrusca). As outras categorias remetem aos estilos de arquitetura, relativos a locais e períodos específicos, enumerados de forma desordenada. No capítulo 4 de Bowvard e Pécuchet, os homenzinhos se embaralham: "Mas o estilo de um monumento não está sempre de acordo com a data que lhe estimam. O arco de volta inteira, no décimo terceiro século domina ainda na Provença. A ogiva é talvez mais antiga! E os autores contestam a anterioridade do romano sobre o gótico. - Essa falta de certeza os contrariava." (BP, p.166)

${ }^{34}$ O caso Laffarge, bastante romanesco, havia seduzido a opinião: Marie Lafarge havia sido acusada de ter envenenado seu marido com arsênico e foi condenada a trabalhos obrigatórios pelo resto da vida em setembro de 1840 , sob provas incertas. Foi indultada em 1852, mas morreu logo em seguida. A história havia sido considerada, provavelmente sem motivo, como uma fonte de Madame Bovary. "Madame Lafarge" é, em todo caso, um dos assuntos de "entusiasmos populares" que Flaubert inscreve no Le Catalogue des idées chic (Catálogo das ideias chiques).

Emma, lembremo-nos, come o arsênico; "ela [...] apanha o frasco azul, arranca a rolha, enfia ali a mão, e, retirando-a cheia de um pó branco, ela se põe a comer assim mesmo.” (B, p. 485)

${ }^{35}$ Como Baudelaire, Flaubert opõe a originalidade da arte e das belas-artes à produção industrial do século XIX - a arte industrial (a produção em série de objetos, móveis, bibelôs, litografias...) e a literatura de massa: "O industrialismo desenvolveu o Feio em proporções gigantescas! Quantos bravos que, há um século, teriam perfeitamente vivido sem Belas-Artes, e a quem é necessário estatuetas pequenas, música pequena e literatura pequena!" (À Louise Colet, 29 de janeiro de 1854). Em seu artigo sobre os comícios, Homais diz ter brindado a saúde "da indústria e das belas-artes, essas duas irmãs!” (B, p. 279)

${ }^{36} \mathrm{Na}$ obra de Flaubert, a "vida de artista" é o ponto de partida de minicenários imaginários estereotipados (vide também: "Atrizes", "Apartamento de solteiro", "Homem jovem"). "Todos esses grandes artistas queimam a vela pelas duas botas; é necessário que eles tenham uma existência desavergonhada que excite um pouco a imaginação. Mas eles morrem no hospital, porque eles não mantiveram o espírito jovem, nem fizeram economia." (B, p.364). Sobre um modo mais farsesco, Bouvard e Pécuchet, em seu período teatral "se consagram artistas. Pécuchet deixou bigodes, e Bouvard, com sua cara redonda e sua calvície, não achou nada melhor do que fazer "uma cara de Béranger!" (BP, p. 213). O significado de "artista" no século XIX é bastante fluido. Equivalente a "comediante", mas também a "poeta" e a "escritor", a palavra pode designar os criadores em geral (de artes plásticas, arquitetura, literatura, música e espetáculo). "ARTISTAS: são todos desinteressados" é o primeiro exemplo que Flaubert oferece em 1852 para ilustrar seu futuro dicionário (À Louise Colet, 16 de dezembro de 1852). 
ÁSPIDE: Animal conhecido pelo cesto de figos de Cléopatra. ${ }^{37}$

ASTRONOMIA: Bela ciência. - Muito É útil apenas para a Marinha. ${ }^{38}$

E, a propósito, rir da Astrologia.

ATEU: "Um povo de ateus não poderia sobreviver". 39

ATRIZES: A perdição dos rapazes de família ${ }^{40}$. São de uma lubricidade fantástica ${ }^{41}$ assustadora, fazenrse entregam a orgias te madrugada, eomen devoram milhões terminam no hospital.

— Perdão, há aquelas que são boas mães de família!

AUTORES: Deve-se "conheeer seus autores" = inútil saber seus nomes. mas é inútil saber inclusive seus nomes. AVESTRUZ: Digere pectras. ${ }^{42}$
${ }^{37}$ Alusão ao suicídio de Cleópatra (v. 69- v. 30) que, dizem, foi mordida por uma serpente áspide escondida em um cesto de figos. A evocação da áspide corresponde ao interesse de Pécuchet pela Cleópatra de Marmontel (1750), tragédia pela qual Vaucanson havia criado uma áspide autômata que sibilava bem alto. "Uma vez na Cleópatra de Marmontel (1750), ele imaginou reproduzir o sibilamento da áspide, da mesma maneira que o animal autômato inventado urgentemente por Vaucanson deveria ter produzido. Esse efeito faltante (gafe) fizeram-lhes rir até a noite" (BP. p. 207)

${ }^{38}$ É a redução do que Pécuchet ensina ao jovem Victor, no capítulo 10 de Bouvard e Pécuchet: "Por uma noite de janeiro, Pécuchet o levou em campo rente. Sempre caminhando, ele preconizava a astronomia; os navegantes a utilizam em suas viagens; Cristóvão Colombo não teria feito sua descoberta sem ela" (BP, p. 380).

${ }^{39}$ Eco da resposta de Voltaire no Dictionnaire philosophique (Dicionário filosófico) (artigo "Ateu, Ateísmo") às questões de Pierre Bayle sobre o ateísmo, em seus Pensées sur la comète (Pensamentos sobre o cometa, 1683): "De todos esses fatos eu passo à questão da moral discutida por Bayle, a saber, se uma sociedade de ateus poderia sobreviver. [...] Em que uma sociedade de ateus parece ser impossível? É que julga-se que os homens sem freio não poderiam jamais viver juntos; que as leis não podem nada contra os crimes secretos; que é preciso um Deus vingador que puna nesse mundo ou em outro os malvados que escaparam da justiça humana." (Ed. GF, 1964, p. 54)

${ }^{40}$ É o imaginário de Homais em Madame Bovary: "E você não sabe a vida que esses farsantes levam com as atrizes no quartier Latin*!” (B, p. 237). Na ocasião da Comuna de Paris, Flaubert denuncia a estupidez da sociedade no fim do segundo Império: "Exaltava-se uma atriz não como uma atriz, mas como boa mãe de família" ('A George Sand, 30 de abril de 1871). *O quartier Latin é um bairro parisiense conhecido por ter reunido artistas e boêmios. Está localizado na margem esquerda do rio Sena. (N. T.)

${ }^{41}$ No sentido de "que procede da imaginação, que depende do imaginário" (daí estranho, sobrenatural) - sentido próximo da "fantasmagoria" (ou "arte de fazer ver fantasmas"), esse espetáculo de lanterna mágica, em voga no século XIX, que projetava sobre uma tela, na escuridão, imagens luminosas e móveis, davam a impressão de chegar perto do espectador. "Fantástico" também não está distante de "fantasmático". A acepção familiar de "fabuloso, inacreditável, extravagante” também está presente no Larousse (1872).

\footnotetext{
${ }^{42}$ Crença popular evocada por J.-B. Salgues, em seu Des erreurs et des préjugés répandus dans la société (Erros e preconceitos espalhados pela sociedade - 3 vol., 1810-1813), citado por Anne Green, p. 774: "Que os Avestruzes devoram pedras, ferro, cobre, vidro, etc., é um fato conhecido." Flaubert conhecia bem a obra de Salgues, que existia em sua biblioteca.
} 


\section{Referéncias OBibliagräficas}

BARTHES, R. Fragments d'un discours amoureux. In: Oeuvres Complètes. V. 5. 1977-1980. Paris: Seuil, 2002. pp. 27-290.

FLAUBERT, G. Le Dictionnaire des Idées Reçues et Le Catalogue des idées chic. Texte établi, présenté et annoté par Anne Herschberg-Pierrot. Paris: Librairie Générale Française/Le livre de poche, 1997. Bouvard et Pécuchet. suivi du Sottisier, de L'Album de la marquise, du Dictionnaire des idées reçues et du catalogue des idées chic. éd. Claudine Gothot-Mersh. Paris: Gallimard/Folio Classique. [1979], 2009

Correspondance. Consulta no site da Université de Rouen. Disponível em: <http:// flaubert.univrouen.fr/index.php>. Acesso em 08 out. de 2011.

. Bouvard e Pécuchet. trad. Mariana Appenzeller. São Paulo: Estação Liberdade, 2007.

. Dicionário das idéias feitas. trad. Cristina Murachco. São Paulo: Nova Alexandria, 1995.

Herschberg-Pierrot Anne. Histoire d'idées reçues'. In: Romantisme, 1994, n86. Langue et idéologie. pp. 101-120. Disponível em: <http://www.persee.fr/web/revues/home/prescript/ article/ roman_0048-8593_1994_num_24_86_5990>. Acesso em 09 out. 2011.

\section{Referências dos comentários de Anne Herschberg-Pierrot (notas de rodapé) presentes nesta tradução}

FLAUBERT, G. Bouvard et Pécuchet, édition critique par Alberto Cento, précédée des scénarios inédits. Naples : Istituto unversitario orientale, Paris : Nizet, 1964.

. Dicionnaire des Idées Reçues. Édition diplomatique des trois manuscrits de Rouen par Lea Caminiti. Naplea, Liguori-Paris : Nizet, 1966.

. Bouvard et Pécuchet. Édition de Claudine Gothot-Mersch. Paris : Gallimard, Folio, 1979.

Le second volume de "Bouvard et Pécuchet ». Le projet du " sottisier ». Reconstitution conjecturale

de la «copie » des deux bonshommes d'après le dossier de Rouen. Édition établie par Alberto Cento et Lea Caminiti Pennarola. Naples : Liguori, 1981.

- Sciocchezzaio, Diquionario dei luoghi comuni, Catalogo delle idee chic. Édition par Lea Caminiti

Pennarola. Milan: Rizzoli, 1992.

La Première Éducation sentimentale (1845). Édition de Martine Bercot. Paris : Le livre de

Poche classique, 1993.

Madame Bovary. Édition de Pierre-Marc de Biasi. Paris : Éd. de l’Imprimerie Nationale,

1994.

Théatre, dans Oeuvres complètes, II. Éditée par bernard Masson. Paris : Seuil, 1964.

Correspondance, I, 1830-1851, édition établie par Jean Bruneau. Paris: Gallimard, 1980.

Correspondance, II, 1851-1858, édition établie par Jean Bruneau. Paris: Gallimard, 1973.

Dictionnaire de la conversation et de la lecture, sous la direction de William Duckett, 2e édition, 16 volumes (1870-1878).

Artigo recebido em: 30 de julho de 2011.

Artigo aceito em: 16 de setembro de 2011.

Referência eletrônica: MESSIAS, Carolina; PINO, Claudia A. Dicionário de ideias aceitas: projeto de tradução. Revista Criação \& Crítica, n. 7, p. 61-70, 2011. Disponível em:<http://www.fflch.usp.br/dlm/criacaoecritica/dmdocuments/ CC_N7_CMessiasCAPino.pdf> 